\title{
Insights into the Mechanism of Nonadiabatic Photodissociation from Product Vibrational Distributions. The Remarkable Case of Phenol
}

Changjian Xie, ${ }^{1,2, \$}$ Bin Zhao, $, \$, \%$ Christopher L. Malbon, ${ }^{3}$ David R. Yarkony, ${ }^{3, *}$ Daiqian Xie, ${ }^{4,}{ }^{*}$ and Hua Guo ${ }^{2, *}$

${ }^{1}$ Institute of Modern Physics, Shaanxi Key Laboratory for Theoretical Physics Frontiers, Northwest University, Xian, Shaanxi 710127, China

${ }^{2}$ Department of Chemistry and Chemical Biology, University of New Mexico, Albuquerque, New Mexico 87131, USA

${ }^{3}$ Department of Chemistry, Johns Hopkins University, Baltimore, Maryland 21218, USA

${ }^{4}$ Institute of Theoretical and Computational Chemistry, Key Laboratory of Mesoscopic Chemistry, School of Chemistry and Chemical Engineering, Nanjing University, Nanjing 210023, China

\section{Supporting Information}

\footnotetext{
\$: These authors contributed equally.

\%: Current address: Theoretische Chemie, Fakultät für Chemie, Universität Bielefeld, Universitätsstr. 25, D-33615 Bielefeld, Germany.

*: Corresponding authors: dqxie@nju.edu.cn. yarkony@jhu.edu, hguo@unm.edu
} 


\section{S-I. Symmetry Consideration}

The total symmetry of a molecular system, including the electronic, vibrational, and rotational symmetries, is conserved during the photodissociation process. As discussed in the main text, the coupled potential energy matrix (PEM) of the four diabatic electronic states ${ }^{1}$ is based on the $G_{4}$ subgroup of the complete nuclear permutation and inversion (CNPI) group, ${ }^{2}$ which is isomorphic to the $C_{2 \mathrm{v}}$ point group, as shown in Table $\mathrm{S} 1$. The ${ }^{1} \pi \pi$ and ${ }^{1} \pi \pi^{*}$ states are of $\mathrm{A}_{1}$ and $\mathrm{B}_{2}$ symmetry, respectively, while the $1^{1} \pi \sigma^{*}$ and $2^{1} \pi \sigma^{*}$ states are of $B_{1}$ and $A_{2}$ symmetry, respectively. For the product $\mathrm{H}+\mathrm{C}_{6} \mathrm{H}_{5} \mathrm{O}\left(\mathrm{X}^{/ / \beta} B_{1}\right)$ channel, its electronic state has $\mathrm{B}_{1}$ symmetry. On the other hand, the rotational symmetry of the product channel $\mathrm{H}+\mathrm{C}_{6} \mathrm{H}_{5} \mathrm{O}$ corresponds to the four irreducible representations of $C_{2 \mathrm{v}}$, which is similar to the asymptotic case of the $\mathrm{Ar}-\mathrm{H}_{2} \mathrm{O}$ complex. ${ }^{3}$ But the $C_{2}$ axis is $I_{b}$ axis for $\mathrm{H}_{2} \mathrm{O}$, which is $I_{a}$ axis for $\mathrm{C}_{6} \mathrm{H}_{5} \mathrm{O}$. In our case, the four symmetries are $\mathrm{A}_{1}=\left(\right.$ even, $K_{a}=$ even $), \mathrm{A}_{2}=\left(\right.$ odd,$K_{a}=$ odd $), \mathrm{B}_{1}=\left(\right.$ odd, $K_{a}=$ even $), \mathrm{B}_{2}=\left(\right.$ even, $K_{a}=$ odd $),{ }^{3}$ in which the first 'even/odd' in the parenthesis is for the inversion parity, and $K_{a}$ (not a good quantum number) is the projection of the total rotational angular momentum of $\mathrm{C}_{6} \mathrm{H}_{5} \mathrm{O}$ on the $I_{a}$ axis for the asymmetric rotor $\mathrm{C}_{6} \mathrm{H}_{5} \mathrm{O}$. The vibrational symmetry of $\mathrm{C}_{6} \mathrm{H}_{5} \mathrm{O}\left(X^{9 / 8} B_{1}\right)$ also has four irreducible representations (shown in Tables S4 and S6 below). Assuming the initial ro-vibrational state is the ground state, the initial overall symmetry on $\mathrm{S}_{1}\left({ }^{1} \pi \pi^{*}\right)$ is $\mathrm{B}_{2}$. So, the final product states of $\Gamma_{\text {elec }} \otimes \Gamma_{\text {vib }} \otimes \Gamma_{\text {rot }}=\mathrm{B}_{2}$ symmetry are required. For the ground state product $\mathrm{H}+\mathrm{C}_{6} \mathrm{H}_{5} \mathrm{O}\left(X^{\natural / \hat{\theta}} B_{1}\right)$ channel, $\Gamma_{\text {elec }}$ is $\mathrm{B}_{1}$. Then the ro-vibrational states of $\Gamma_{\text {vib }} \otimes \Gamma_{\text {rot }}=A_{2}$ symmetry are allowed. From Table $\mathrm{S} 1$, the combinations $\mathrm{A}_{1} \otimes \mathrm{A}_{2}$ or $\mathrm{B}_{1} \otimes \mathrm{B}_{2}$ for the symmetries of the vibrations and rotations are both available. In other words, all the vibrational states are allowed when the rotational modes are included. The correlation between the $C_{2 \mathrm{v}}$ and $C_{\mathrm{s}}$ symmetries is shown in Table $\mathrm{S} 2$. 


\section{S-II. Quantum Dynamic Model}

The nuclear Hamiltonian in the diabatic representation is given as follows:

$$
\hat{H}=\mathbf{T}+\mathbf{H}^{d,(4)}=\hat{T}\left(\begin{array}{llll}
1 & 0 & 0 & 0 \\
0 & 1 & 0 & 0 \\
0 & 0 & 1 & 0 \\
0 & 0 & 0 & 1
\end{array}\right)+\left(\begin{array}{llll}
V_{11} & V_{12} & V_{13} & V_{14} \\
V_{21} & V_{22} & V_{23} & V_{24} \\
V_{31} & V_{32} & V_{33} & V_{34} \\
V_{41} & V_{42} & V_{43} & V_{44}
\end{array}\right)
$$

in which the diabatic potential terms in $\mathbf{H}^{d,(4)}$ are defined in a previous study. ${ }^{1} V_{11}, V_{22}, V_{33}$, and $V_{44}$ are the potential energies of the four diabatic electronic states, corresponding to the $1^{1} \pi \sigma^{*},{ }^{1} \pi \pi^{*}$, $2^{1} \pi \sigma^{*}$, and ${ }^{1} \pi \pi$ states, respectively. The off-diagonal elements are the couplings among the diabatic electronic states. The corresponding adiabatic potential energy surfaces (PESs) (shown in Fig. 1) can be obtained by diagonalizing this four-state diabatic PEM.

Assuming a zero total angular momentum $\left(J_{t o t}=0\right)$, the four-dimensional (4D) kinetic energy operator $\hat{T}$ in coordinates $(Q, R, \theta, \phi)$ can be approximated as $(\mathrm{h}=1$ hereafter):

$$
\hat{T}=-\frac{\omega_{Q}}{2} \frac{\partial^{2}}{\partial Q^{2}}-\frac{1}{2 \mu_{R}} \frac{\partial^{2}}{\partial R^{2}}+\frac{\hat{j}^{2}}{2 \mu_{R} R^{2}}+\hat{K}^{r o t}
$$

where $\mu_{R}=\frac{m_{\mathrm{H}} m_{\mathrm{C}_{6} \mathrm{H}_{5} \mathrm{O}}}{m_{\mathrm{H}}+m_{\mathrm{C}_{6} \mathrm{H}_{5} \mathrm{O}}}$ is the corresponding reduced mass. $\omega_{Q}$ is the frequency of the additional normal mode of the product $\mathrm{C}_{6} \mathrm{H}_{5} \mathrm{O}$ (all thirty normal modes are shown in Fig. S1). $\hat{j}^{2}$ is the squared rotational angular momentum operator of $\mathrm{C}_{6} \mathrm{H}_{5} \mathrm{O}$. The rotational kinetic energy operator $\hat{K}^{\text {rot }}$ of $\mathrm{C}_{6} \mathrm{H}_{5} \mathrm{O}$, which is an asymmetric top, can be approximated as

$$
\hat{K}^{r o t}=\frac{\hat{j}_{a}^{2}}{2 I_{a}}+\frac{\hat{j}_{b}^{2}}{2 I_{b}}+\frac{\hat{j}_{c}^{2}}{2 I_{c}}
$$


with $\hat{j}^{2}=\hat{j}_{a}^{2}+\hat{j}_{b}^{2}+\hat{j}_{c}^{2}$. The moments of inertia are a function of $Q$.

In the diabatic representation, there are four nuclear wavefunctions associated with the four electronic states:

$$
\Psi=\left(\begin{array}{l}
\psi^{1} \\
\psi^{2} \\
\psi^{3} \\
\psi^{4}
\end{array}\right) .
$$

Each nuclear wavefunction is expanded in a direct-product basis in a mixed representation:

$$
\psi^{i}=\sum_{\alpha \beta j m} C_{\alpha \beta j m}^{i}|\alpha\rangle|\beta\rangle|j m\rangle, \quad i=1,2,3,4,
$$

in which $C_{\alpha \beta \gamma j m}^{i}$ are the expansion coefficients, $\alpha$ denotes the DVR (discrete variable representation) ${ }^{4}$ grid index for $R$, and $\beta$ the PODVR (potential optimized DVR) $)^{4}$ grid index for $Q$. $|j m\rangle$ is the spherical harmonics $N e^{i m \phi} P_{j}^{m}(\theta)$, where $P_{j}^{m}(\theta)$ is the associated Legendre polynomial, $m$ is the projection of $j$ onto the $I_{a}$ axis of $\mathrm{C}_{6} \mathrm{H}_{5} \mathrm{O}$, and $N$ is the normalization factor.

The ${ }^{1} \pi \pi^{*} \leftarrow{ }^{1} \pi \pi$ photoexcitation was simulated within the Condon approximation, in which the initial wave packet on the ${ }^{1} \pi \pi^{*}$ state PES is from the $v_{\mathrm{OH}}=1$ vibrational state eigenfunction on the ground state $\left(\mathrm{S}_{0}\right)$ PES. As discussed in the main text, this choice was made to avoid the exceedingly slow dissociation in the $v_{\mathrm{OH}}=0$ vibrational state, but is not expected to impact the product state distribution because the $\mathrm{OH}$ stretch is the dissociation mode. The initial wave packet is then propagated in the Chebyshev order $(k)$ domain: ${ }^{5}$

$$
\Psi_{k}=2 D \hat{H}_{s} \Psi_{k-1}-D^{2} \Psi_{k-2}, \quad k \geq 2,
$$


with $\Psi_{1}=D \hat{H}_{s} \Psi_{0}$ where $\Psi_{0}$ is the initial wave packet. The Hamiltonian defined in Eq. (1) is scaled to the spectral range of $(-1,1)$ via $\hat{H}_{s}=\left(\hat{H}-H^{+}\right) / H^{-}$, in which the spectral medium and half width $\left(H^{ \pm}=\left(H_{\max } \pm H_{\text {min }}\right) / 2\right)$ were determined by the spectral extrema, $H_{\max }$ and $H_{\min }$, which can be readily estimated. To avoid artificial reflections, damping functions $(D$, with form given in Table S3) were used at the edge of the $R$ grid.

The populations of all energetically available ro-vibrational products were obtained from discrete Fourier transformation: 6

$$
A_{f}(E)=\left|\frac{1}{2 \pi H^{-} \sin \vartheta} \sum_{k=0}^{N}\left(2-\delta_{k 0}\right) e^{-i k \vartheta} C_{k}^{f}\right|^{2},
$$

where $E$ is the total energy of the corresponding excited state resonance, which is related to the Chebyshev angle: $\vartheta=\arccos E . C_{k}^{f}$ are the corresponding Chebyshev correlation functions, which were calculated by

$$
C_{k}^{f}=\left\langle\varphi_{f} \delta\left(R-R^{\infty}\right) \mid \xi_{k}^{1}\right\rangle,
$$

where $\varphi_{f}$ are the $3 \mathrm{D}$ ro-vibrational eigenstates of the product $\mathrm{C}_{6} \mathrm{H}_{5} \mathrm{O} . \xi_{k}^{1}$ are the $k$ th adiabatic wave packets, and $R$ was fixed at $R^{\infty}=20.0 \mathrm{bohr}$ in the product channel $\mathrm{H}+\mathrm{C}_{6} \mathrm{H}_{5} \mathrm{O}(X)$. The numerical parameters used in the 4D quantum dynamics calculations are summarized in Table S3. It should be noted that complete dissociation was not achieved because of the long lifetimes of the resonances, but the relative ro-vibrational state distributions of the products have converged at $\sim 5000$ propagation steps. 
Table S4 lists the calculated anharmonic vibrational frequencies of the ground and excited states of $\mathrm{C}_{6} \mathrm{H}_{5} \mathrm{O}$ with the $4 \mathrm{D}$ models, with the available experimental ${ }^{7,8}$ and theoretical ${ }^{7,9,10}$ results included for comparison. By and large, our calculated frequencies are consistent with previous theoretical and experimental results. In addition, the rotational constants $(A, B$, and $C)$ of $\mathrm{C}_{6} \mathrm{H}_{5} \mathrm{O}(X)$ and $\mathrm{C}_{6} \mathrm{H}_{5} \mathrm{O}(A)$, the dissociation energy $\left(D_{0}\right)$ of $\mathrm{C}_{6} \mathrm{H}_{5} \mathrm{OH}\left(\mathrm{S}_{0}\right)$ to the $\mathrm{H}+\mathrm{C}_{6} \mathrm{H}_{5} \mathrm{O}(X)$ channel, and the $A \leftarrow X$ adiabatic excitation energy $(\Delta E)$ of $\mathrm{C}_{6} \mathrm{H}_{5} \mathrm{O}$ were calculated using the $4 \mathrm{D}$ models as well (see Table S5). It can be seen from the table that the rotational constants of both $\mathrm{C}_{6} \mathrm{H}_{5} \mathrm{O}(X)$ and $\mathrm{C}_{6} \mathrm{H}_{5} \mathrm{O}(A)$ are largely insensitive to the vibrational mode included in the $4 \mathrm{D}$ models. The calculated rotational constants $\left(A=\sim 0.19 \mathrm{~cm}^{-1}, B=\sim 0.09 \mathrm{~cm}^{-1}\right.$, and $\left.C=\sim 0.06 \mathrm{~cm}^{-1}\right)$ for $\mathrm{C}_{6} \mathrm{H}_{5} \mathrm{O}(X)$ and $\mathrm{C}_{6} \mathrm{H}_{5} \mathrm{O}(A)$ are consistent with previous calculated results $\left(A=\sim 0.18 / 0.19 \mathrm{~cm}^{-1}, B=\sim 0.09 / 0.09 \mathrm{~cm}^{-1}\right.$, and $C=\sim 0.06 / 0.06 \mathrm{~cm}^{-1}$ for $\left.\mathrm{C}_{6} \mathrm{H}_{5} \mathrm{O}(X) / \mathrm{C}_{6} \mathrm{H}_{5} \mathrm{O}(A)\right)$ at the B3LYP/aug-cc-pVTZ level. ${ }^{8}$ For $D_{0}$ of phenol and $\Delta E$ of $\mathrm{C}_{6} \mathrm{H}_{5} \mathrm{O}$, all the models almost generate the same values ( $\sim 3.90$ and $\left.\sim 0.91 \mathrm{eV}\right)$, except for the $v_{19 \mathrm{a}}$ mode in which the values are 3.66 and $1.10 \mathrm{eV}$, respectively. The large discrepancy of the $v_{19 \mathrm{a}}$ mode arises from the large difference (-1.888 a.u.) in the equilibrium $v_{19 \mathrm{a}}$ normal mode coordinate between $\mathrm{C}_{6} \mathrm{H}_{5} \mathrm{OH}\left(\mathrm{S}_{0}\right)$ and $\mathrm{C}_{6} \mathrm{H}_{5} \mathrm{O}(X)$, as shown in Table S6. For all the $4 \mathrm{D}$ models, the calculated $D_{0}$ and $\Delta E$ values are both close to available theoretical ${ }^{9,10}$ and experimental ${ }^{8,11,12}$ results as shown in Table S5. The reasonably good agreement validates the 4D models. 
Table S1. Character table of the $G_{4}$ group and equivalence with the point group $C_{2 \mathrm{v}}$.

\begin{tabular}{ccccc}
\hline$G_{4}$ & $E$ & $(12)$ & $(12)^{*}$ & $E^{*}$ \\
\hline$C_{2 \mathrm{v}}$ & $E$ & $C_{2}(z)$ & $\sigma_{\mathrm{h}}(x z)$ & $\sigma_{\mathrm{v}}(y z)$ \\
\hline $\mathrm{A}_{1}$ & 1 & 1 & 1 & 1 \\
$\mathrm{~A}_{2}$ & 1 & 1 & -1 & -1 \\
$\mathrm{~B}_{1}$ & 1 & -1 & 1 & -1 \\
$\mathrm{~B}_{2}$ & 1 & -1 & -1 & 1 \\
\hline
\end{tabular}

$E$ : Identity; (12): the permutation of two identical nuclei numbered 1 and $2 ; E^{*}$ : inversion; $(12)^{*}$ : inversion after doing (12). ${ }^{2}$ 
Table S2. Correlation table for the point groups $C_{2 \mathrm{v}}$ and $C_{\mathrm{s}}$.

\begin{tabular}{cc}
\hline$C_{2 \mathrm{v}}$ & $C_{\mathrm{s}}\left(\sigma_{\mathrm{v}}(y z)\right)$ \\
\hline $\mathrm{A}_{1}$ & $\mathrm{~A}^{\prime}$ \\
$\mathrm{A}_{2}$ & $\mathrm{~A}^{\prime \prime}$ \\
$\mathrm{B}_{1}$ & $\mathrm{~A}^{\prime \prime}$ \\
$\mathrm{B}_{2}$ & $\mathrm{~A}^{\prime}$ \\
\hline
\end{tabular}


Table S3. Numerical parameters (in a.u.) used in the wave packet calculations.

Grid/basis range and size:
$R \in[3.0,23.0], N_{R}=140 ;$
6 PODVR for $v_{16 a}, v_{16 b}, v_{6 a}, v_{18 b}$,
$N_{j}=76$ over $\left[0,180^{\circ}\right] ; N_{\varphi}=151$ over $\left[-180^{\circ}, 180^{\circ}\right]$
Damping:
$D=\exp \left[-0.08\left(\frac{R-20.4}{R-R_{\text {end }}}\right)^{2}\right]$, for $23.0>R>20.4$ with $R_{\text {end }}=23.0 ;$
$\quad=1$, otherwise
Propagation steps:
10000


Table S4. Vibrational frequencies (in $\mathrm{cm}^{-1}$ ) of products $\mathrm{C}_{6} \mathrm{H}_{5} \mathrm{O}(X)$ and $\mathrm{C}_{6} \mathrm{H}_{5} \mathrm{O}(A)$ in the $4 \mathrm{D}$ models. The symmetry of the modes is labeled in $C_{s} / C_{2 \mathrm{v}}$. The symbols of normal modes referred to Wilson's nomenclature (Ref. 13). The $\mathrm{C}_{6} \mathrm{H}_{5} \mathrm{O}(A)$ vibrational modes for other calculated ${ }^{10}$ and experimental results ${ }^{8}$ were assigned following Ref. 7.

\begin{tabular}{|c|c|c|c|c|c|c|c|c|c|}
\hline \multirow{3}{*}{ Mode } & \multirow{3}{*}{ Sym. } & \multicolumn{8}{|c|}{ Vibrational frequency } \\
\hline & & \multicolumn{4}{|c|}{$\mathrm{C}_{6} \mathrm{H}_{6} \mathrm{O}(X)$} & \multicolumn{4}{|c|}{$\mathrm{C}_{6} \mathrm{H}_{6} \mathrm{O}(A)$} \\
\hline & & This work & Calc. ${ }^{\mathrm{a}}$ & Calc. $^{b}$ & Expt. $^{b}$ & This work & Calc. $^{\mathrm{c}}$ & Calc. $^{\mathrm{d}}$ & Expt. $^{\mathrm{e}}$ \\
\hline $20 a$ & $a^{\prime} / a_{1}$ & 3367.4 & 3079.5 & 3199 & 3090 & 3328.1 & 3100 & 3107 & \\
\hline $20 b$ & $a^{\prime} / b_{2}$ & 3444.7 & 3065.6 & 3196 & 3074 & 3457.5 & 3099 & 3106 & \\
\hline 13 & $a^{\prime} / a_{1}$ & 3317.3 & 3007.9 & 3188 & 3065 & 3310.7 & 3091 & 9098 & \\
\hline 2 & $a^{\prime} / a_{1}$ & 3418.0 & 3053.8 & 3166 & 3018 & 3413.9 & 3062 & 3070 & \\
\hline $7 b$ & $a^{\prime} / b_{2}$ & 3362.3 & 3042.9 & 3172 & 3054 & 3384.6 & 3067 & 3075 & \\
\hline $19 a$ & $a^{\prime} / a_{1}$ & 1574.6 & 1450.6 & 1422 & 1397 & 1759.2 & 1202 & 1201 & \\
\hline $8 a$ & $a^{\prime} / a_{1}$ & 1538.2 & 1545 & 1589 & 1550 & 1579.5 & 1556 & 1556 & \\
\hline $8 b$ & $a^{\prime} / b_{2}$ & 1749.0 & 1511.4 & 1149 & 1441 & 1704.7 & 1408 & 1395 & \\
\hline $19 b$ & $a^{\prime} / b_{2}$ & 1613.6 & 1412.2 & 1550 & 1515 & 1590.3 & 1529 & 1529 & \\
\hline $7 a$ & $a^{\prime} / a_{1}$ & 1473.8 & 1394 & 1482 & 1481 & 1440.8 & 1410 & 1393 & \\
\hline 3 & $a^{\prime} / b_{2}$ & 1442.8 & 1246.1 & 1277 & 1266 & 1447.7 & 1222 & 1232 & \\
\hline 14 & $a^{\prime} / b_{2}$ & 1451.9 & 1317.1 & 1340 & 1318 & 1404.2 & 1304 & 1291 & \\
\hline $9 a$ & $a^{\prime} / a_{1}$ & 1262.6 & 1150.5 & 1167 & 1167 & 1286.0 & 1152 & 1143 & \\
\hline 15 & $a^{\prime} / b_{2}$ & 1164.6 & 1074.2 & 1167 & 1140 & 1149.1 & 1139 & 1130 & \\
\hline $9 b$ & $a^{\prime} / b_{2}$ & 1239.1 & 1149.9 & 1092 & 1072 & 1260.7 & 1058 & 1052 & \\
\hline $18 a$ & $a^{\prime} / a_{1}$ & 1106.0 & 992.2 & 991 & 977 & 1096.4 & 961 & 953 & \\
\hline 1 & $a^{\prime} / a_{1}$ & 1061.6 & 966.5 & 807 & 813 & 1059.9 & 802 & 797 & \\
\hline $17 a$ & $a^{\prime \prime} / a_{2}$ & 1087.5 & 985.6 & 996 & & 1079.5 & 941 & 928 & $947 \pm 2$ \\
\hline 5 & $a^{\prime \prime} / a_{2}$ & 1035.1 & \begin{tabular}{|l|}
972.7 \\
\end{tabular} & 1010 & 1016 & 1034.9 & 955 & 943 & $964 \pm 5$ \\
\hline $17 b$ & $a^{\prime \prime} / b_{1}$ & 981.1 & 909.6 & 936 & 898 & 945.5 & 861 & 847 & $866 \pm 3$ \\
\hline 12 & $a^{\prime} / a_{1}$ & 895.0 & 790.2 & 1011 & 1038 & 921.9 & 1011 & 1008 & \\
\hline $10 a$ & $a^{\prime \prime} / a_{2}$ & 875.8 & 794.4 & 809 & & 914.8 & 799 & 787 & $793 \pm 6$ \\
\hline $10 b$ & $a^{\prime \prime} / b_{1}$ & 871.3 & 788.5 & 660 & 635 & 817.6 & 673 & 674 & $680 \pm 2$ \\
\hline 4 & $a^{\prime \prime} / b_{1}$ & 661.6 & 647 & 808 & 784 & 646.3 & 710 & 697 & $723 \pm 2$ \\
\hline $6 b$ & $a^{\prime} / b_{2}$ & 636.7 & 590.2 & 599 & 616 & 687.3 & 604 & 599 & \\
\hline $6 a$ & $a^{\prime} / a_{1}$ & 535.7 & 525.3 & 533 & 520 & 557.4 & 505 & 501 & \\
\hline $16 b$ & $a^{\prime \prime} / b_{1}$ & 503.7 & 476.9 & 487 & 472 & 524.8 & 496 & 490 & $499 \pm 5$ \\
\hline $18 b$ & $a^{\prime} / b_{2}$ & 506.6 & 442.8 & 447 & 446 & 441.7 & 358 & 354 & \\
\hline $16 a$ & $a^{\prime \prime} / a_{2}$ & 431.7 & 372.9 & 383 & & 456.4 & 416 & 414 & $417 \pm 2$ \\
\hline 11 & $a^{\prime \prime} / b_{1}$ & 227.7 & 184.8 & 191 & & 257.3 & 219 & 218 & \\
\hline
\end{tabular}

${ }^{\text {aRef. } 9 .}$

${ }^{\text {bRef. } 7 . ~ A s s i g n m e n t s ~ o f ~} v_{11}$ and $v_{10 \mathrm{~b}}$ in Ref. 7 were exchanged.

${ }^{\mathrm{c} C a l c u l a t e d}$ at B3LYP/aug-cc-pVTZ level in Ref. 10.

${ }^{\mathrm{d} C a l c u l a t e d}$ at B3LYP/aug-cc-pVDZ level in Ref. 10.

eRef. 8. 
Table S5. Rotational constants $A, B$, and $C$ (in $\mathrm{cm}^{-1}$ ) of products $\mathrm{C}_{6} \mathrm{H}_{5} \mathrm{O}(X)$ and $\mathrm{C}_{6} \mathrm{H}_{5} \mathrm{O}(A)$, the dissociation energy $\left(D_{0}\right.$, in $\left.\mathrm{eV}\right)$ of $\mathrm{C}_{6} \mathrm{H}_{5} \mathrm{OH}\left(\mathrm{S}_{0}\right)$, and the adiabatic excitation energy $(\Delta E$, in $\mathrm{eV})$ of $\mathrm{C}_{6} \mathrm{H}_{5} \mathrm{O}(A) \leftarrow \mathrm{C}_{6} \mathrm{H}_{5} \mathrm{O}(X)$ in the $4 \mathrm{D}$ models.

\begin{tabular}{|c|c|c|c|c|c|c|c|c|c|c|c|}
\hline \multirow{3}{*}{ Mode } & \multicolumn{6}{|c|}{ Rotational constants } & \multicolumn{2}{|c|}{$D_{0}$} & \multicolumn{3}{|c|}{$\Delta E$} \\
\hline & \multicolumn{3}{|c|}{$\mathrm{C}_{6} \mathrm{H}_{5} \mathrm{O}(X)$} & \multicolumn{3}{|c|}{$\mathrm{C}_{6} \mathrm{H}_{5} \mathrm{O}(A)$} & \multirow{2}{*}{$\begin{array}{l}\text { This } \\
\text { work }\end{array}$} & \multirow[t]{2}{*}{ Expt. } & \multirow{2}{*}{$\begin{array}{l}\text { This } \\
\text { work }\end{array}$} & \multirow[t]{2}{*}{ Calc. } & \multirow[t]{2}{*}{ Expt. } \\
\hline & $A$ & $B$ & $C$ & $A$ & $B$ & $C$ & & & & & \\
\hline $20 a$ & 0.1900 & 0.0905 & 0.0613 & 0.1900 & 0.0905 & 0.0613 & 3.907 & \multirow{30}{*}{$\mid \begin{array}{l}3.721 \pm \\
0.005^{\mathrm{a}}\end{array}$} & 0.906 & \multirow{30}{*}{$\begin{array}{l}0.898^{b} \\
0.908^{c}\end{array}$} & \multirow{30}{*}{$\begin{array}{c}0.952^{\mathrm{d}} \\
1.06(5)^{\mathrm{e}}\end{array}$} \\
\hline $20 b$ & 0.1901 & 0.0905 & 0.0613 & 0.1901 & 0.0905 & 0.0613 & 3.906 & & 0.909 & & \\
\hline 13 & 0.1901 & 0.0905 & 0.0613 & 0.1901 & 0.0905 & 0.0613 & 3.905 & & 0.907 & & \\
\hline 2 & 0.1901 & 0.0905 & 0.0613 & 0.1901 & 0.0905 & 0.0613 & 3.905 & & 0.908 & & \\
\hline $7 b$ & 0.1901 & 0.0905 & 0.0613 & 0.1901 & 0.0905 & 0.0613 & 3.905 & & 0.909 & & \\
\hline $19 a$ & 0.1901 & 0.0910 & 0.0615 & 0.1901 & 0.0905 & 0.0613 & 3.662 & & 1.148 & & \\
\hline $8 a$ & 0.1900 & 0.0905 & 0.0613 & 0.1901 & 0.0905 & 0.0613 & 3.888 & & 0.923 & & \\
\hline $8 b$ & 0.1901 & 0.0905 & 0.0613 & 0.1901 & 0.0905 & 0.0613 & 3.906 & & 0.905 & & \\
\hline $19 b$ & 0.1901 & 0.0905 & 0.0613 & 0.1901 & 0.0905 & 0.0613 & 3.903 & & 0.907 & & \\
\hline $7 a$ & 0.1900 & 0.0905 & 0.0613 & 0.1901 & 0.0905 & 0.0613 & 3.886 & & 0.924 & & \\
\hline 3 & 0.1901 & 0.0905 & 0.0613 & 0.1901 & 0.0905 & 0.0613 & 3.903 & & 0.909 & & \\
\hline 14 & 0.1901 & 0.0905 & 0.0613 & 0.1901 & 0.0905 & 0.0613 & 3.908 & & 0.905 & & \\
\hline $9 a$ & 0.1895 & 0.0907 & 0.0613 & 0.1900 & 0.0905 & 0.0613 & 3.894 & & 0.918 & & \\
\hline 15 & 0.1901 & 0.0905 & 0.0613 & 0.1901 & 0.0905 & 0.0613 & 3.902 & & 0.908 & & \\
\hline $9 b$ & 0.1901 & 0.0905 & 0.0613 & 0.1901 & 0.0905 & 0.0613 & 3.902 & & 0.910 & & \\
\hline $18 a$ & 0.1902 & 0.0905 & 0.0613 & 0.1902 & 0.0905 & 0.0613 & 3.903 & & 0.907 & & \\
\hline 1 & 0.1893 & 0.0903 & 0.0611 & 0.1900 & 0.0905 & 0.0613 & 3.900 & & 0.911 & & \\
\hline $17 a$ & 0.1900 & 0.0905 & 0.0613 & 0.1900 & 0.0905 & 0.0613 & 3.909 & & 0.908 & & \\
\hline 5 & 0.1900 & 0.0905 & 0.0613 & 0.1900 & 0.0905 & 0.0613 & 3.908 & & 0.908 & & \\
\hline $17 b$ & 0.1900 & 0.0905 & 0.0613 & 0.1900 & 0.0905 & 0.0613 & 3.907 & & 0.906 & & \\
\hline 12 & 0.1875 & 0.0899 & 0.0608 & 0.1905 & 0.0905 & 0.0614 & 3.890 & & 0.921 & & \\
\hline $10 a$ & 0.1900 & 0.0905 & 0.0613 & 0.1900 & 0.0905 & 0.0613 & 3.903 & & 0.911 & & \\
\hline $10 b$ & 0.1900 & 0.0905 & 0.0613 & 0.1900 & 0.0905 & 0.0613 & 3.907 & & 0.904 & & \\
\hline 4 & 0.1900 & 0.0905 & 0.0613 & 0.1900 & 0.0905 & 0.0613 & 3.901 & & 0.907 & & \\
\hline $6 b$ & 0.1901 & 0.0905 & 0.0613 & 0.1900 & 0.0905 & 0.0613 & 3.893 & & 0.912 & & \\
\hline $6 a$ & 0.1871 & 0.0923 & 0.0618 & 0.1892 & 0.0911 & 0.0615 & 3.886 & & 0.923 & & \\
\hline $16 b$ & 0.1900 & 0.0905 & 0.0613 & 0.1900 & 0.0905 & 0.0613 & 3.902 & & 0.909 & & \\
\hline $18 b$ & 0.1900 & 0.0905 & 0.0613 & 0.1900 & 0.0905 & 0.0613 & 3.892 & & 0.910 & & \\
\hline $16 a$ & 0.1900 & 0.0905 & 0.0613 & 0.1900 & 0.0905 & 0.0613 & 3.904 & & 0.910 & & \\
\hline 11 & 0.1900 & 0.0905 & 0.0613 & 0.1899 & 0.0904 & 0.0613 & 3.906 & & 0.907 & & \\
\hline
\end{tabular}

${ }^{\text {aRef. } 9 .}$

${ }^{b}$ Calculated at B3LYP/aug-cc-pVTZ level in Ref. 10.

${ }^{c}$ Calculated at B3LYP/aug-cc-pVDZ level in Ref. 10.

${ }^{\text {dRef. } 8 .}$.

eData from Refs. 11, 12. 
Table S6. Normal mode coordinates displacements ( $\Delta Q$ in a.u.) of important geometry structures in the photodissociation process with respect to the equilibrium geometry of the ground state phenol $\mathrm{C}_{6} \mathrm{H}_{5} \mathrm{OH}\left(\mathrm{S}_{0}\right)$. MEX stands for minimum energy conical intersection.

\begin{tabular}{|c|l|c|c|c|c|c|}
\hline Mode & $\mathrm{Sym}$. & $\mathrm{C}_{6} \mathrm{H}_{6} \mathrm{OH}\left(\mathrm{S}_{2}\right)$ & $\mathrm{C}_{6} \mathrm{H}_{6} \mathrm{O}(X)$ & $\mathrm{C}_{6} \mathrm{H}_{6} \mathrm{O}(A)$ & $\mathrm{MEX}\left(\mathrm{S}_{1}-\mathrm{S}_{2}\right)$ & $\mathrm{MEX}\left(\mathrm{S}_{0}-\mathrm{S}_{1}\right)$ \\
\hline $20 a$ & $a^{\prime} / a_{1}$ & -0.061 & -0.022 & 0.018 & -0.073 & -0.031 \\
\hline $20 b$ & $a^{\prime} / b_{2}$ & -0.016 & -0.010 & -0.010 & -0.023 & -0.025 \\
\hline 13 & $a^{\prime} / a_{1}$ & -0.014 & -0.005 & 0.016 & -0.014 & -0.008 \\
\hline 2 & $a^{\prime} / a_{1}$ & 0.005 & 0.003 & 0.003 & 0.010 & 0.008 \\
\hline $7 b$ & $a^{\prime} / b_{2}$ & 0.006 & -0.003 & -0.002 & 0.002 & -0.005 \\
\hline $19 a$ & $a^{\prime} / a_{1}$ & -1.488 & -1.888 & -0.110 & -1.363 & -1.634 \\
\hline $8 a$ & $a^{\prime} / a_{1}$ & 0.378 & 0.755 & 0.135 & 0.520 & 0.643 \\
\hline $8 b$ & $a^{\prime} / b_{2}$ & -0.002 & 0.062 & 0.062 & 0.043 & 0.033 \\
\hline $19 b$ & $a^{\prime} / b_{2}$ & 0.021 & -0.087 & -0.087 & -0.023 & -0.010 \\
\hline $7 a$ & $a^{\prime} / a_{1}$ & 0.520 & 0.820 & 0.080 & 0.551 & 0.649 \\
\hline 3 & $a^{\prime} / b_{2}$ & -0.017 & 0.046 & 0.046 & 0.006 & -0.017 \\
\hline 14 & $a^{\prime} / b_{2}$ & -0.022 & 0.071 & 0.071 & 0.013 & 0.026 \\
\hline $9 a$ & $a^{\prime} / a_{1}$ & 0.588 & 0.518 & 0.034 & 0.411 & 0.478 \\
\hline 15 & $a^{\prime} / b_{2}$ & -0.007 & -0.121 & -0.121 & 0.004 & -0.041 \\
\hline $9 b$ & $a^{\prime} / b_{2}$ & -0.076 & -0.039 & -0.039 & -0.037 & 0.003 \\
\hline $18 a$ & $a^{\prime} / a_{1}$ & 0.300 & 0.165 & 0.186 & 0.225 & 0.224 \\
\hline 1 & $a^{\prime} / a_{1}$ & 0.349 & 0.299 & 0.057 & 0.445 & 0.246 \\
\hline $17 a$ & $a^{\prime \prime} / a_{2}$ & 0.000 & 0.000 & 0.000 & 0.000 & 0.000 \\
\hline 5 & $a^{\prime \prime} / a_{2}$ & 0.000 & 0.000 & 0.000 & 0.000 & 0.000 \\
\hline $17 b$ & $a^{\prime \prime} / b_{1}$ & 0.000 & 0.000 & 0.000 & 0.000 & 0.000 \\
\hline 12 & $a^{\prime} / a_{1}$ & -0.195 & -0.208 & 0.180 & -0.398 & -0.120 \\
\hline $10 a$ & $a^{\prime \prime} / a_{2}$ & 0.000 & 0.000 & 0.000 & 0.000 & 0.000 \\
\hline $10 b$ & $a^{\prime \prime} / b_{1}$ & 0.000 & 0.000 & 0.000 & 0.000 & 0.000 \\
\hline 4 & $a^{\prime \prime} / b_{1}$ & 0.000 & 0.000 & 0.000 & 0.000 & 0.000 \\
\hline $6 b$ & $a^{\prime} / b_{2}$ & -0.337 & -0.304 & -0.304 & -0.078 & -0.173 \\
\hline $6 a$ & $a^{\prime} / a_{1}$ & 1.311 & 0.751 & 0.302 & 0.931 & 0.598 \\
\hline $16 b$ & $a^{\prime \prime} / b_{1}$ & 0.000 & 0.000 & 0.000 & 0.000 & 0.000 \\
\hline $18 b$ & $a^{\prime} / b_{2}$ & -0.162 & 0.684 & 0.684 & -0.044 & 0.251 \\
\hline $16 a$ & $a^{\prime \prime} / a_{2}$ & 0.000 & 0.000 & 0.000 & 0.000 & 0.000 \\
\hline 11 & $a^{\prime \prime} / b_{1}$ & 0.000 & 0.000 & 0.000 & 0.000 & 0.000 \\
\hline
\end{tabular}




\section{References:}

1. Zhu, X.; Yarkony, D. R. On the elimination of the electronic structure bottleneck in on the fly nonadiabatic dynamics for small to moderate sized (10-15 atom) molecules using fit diabatic representations based solely on ab initio electronic structure data: The photodissociation of phenol, J. Chem. Phys. 2016, 144, 024105.

2. Bunker, P. R.; Jensen, P. Molecular Symmetry and Spectroscopy. NRC Research Press: Ottawa, 1998.

3. Cohen, R. C.; Saykally, R. J. Determination of an improved intermolecular global potential energy surface for $\mathrm{Ar}-\mathrm{H}_{2} \mathrm{O}$ from vibration-rotation-tunneling spectroscopy, J. Chem. Phys. 1993, 98, 6007-6030. 4. Light, J. C.; Carrington Jr., T. Discrete-variable representations and their utilization, Adv. Chem. Phys. 2000, 114, 263-310.

5. Guo, H. Recursive solutions to large eigenproblems in molecular spectroscopy and reaction dynamics, Rev. Comput. Chem. 2007, 25, 285-347.

6. Balint-Kurti, G. G. Time-dependent and time-independent wavepacket approaches to reactive scattering and photodissociation dynamics, Int. Rev. Phys. Chem. 2008, 27, 507-539.

7. Spanget-Larsen, J.; Gil, M.; Gorski, A.; Blake, D. M.; Waluk, J.; Radziszewski, J. G. Vibrations of the phenoxyl radical, J. Am. Chem. Soc. 2001, 123, 11253-11261.

8. Cheng, C.-W.; Witek, H.; Lee, Y.-P. Rovibronic bands of the $\tilde{A}^{2} B_{2} \leftarrow \mathrm{X}^{2} B_{1}$ transition of $\mathrm{C}_{6} \mathrm{H}_{5} \mathrm{O}$ and

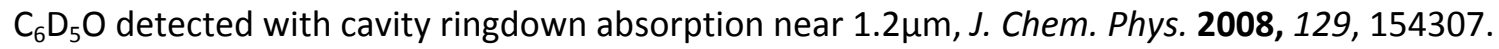

9. Nix, M. G. D.; Devine, A. L.; Cronin, B.; Dixon, R. N.; Ashfold, M. N. R. High resolution photofragment translational spectroscopy studies of the near ultraviolet photolysis of phenol, J. Chem. Phys. 2006, 125, 133318.

10. Cheng, C.-W.; Lee, Y.-P.; Witek, H. A. Theoretical investigation of molecular properties of the first excited state of the phenoxyl radical, J. Phys. Chem. A 2008, 112, 2648-2657.

11. Ward, B. Absorption spectra of aromatic free radicals: a vibraitonal analysis of the $3050 \mathrm{~A}$ absorption spectrum of benzyl and a new transition of phenoxyl, Spectrochim Acta A 1968, 24, 813-818.

12. King, G. A.; Oliver, T. A. A.; Nix, M. G. D.; Ashfold, M. N. R. High resolution photofragment translational spectroscopy studies of the ultraviolet photolysis of phenol- $d_{5}$, J. Phys. Chem. A 2009, 113, 7984-7993.

13. Wilson, E. B. The normal modes and frequencies of vibration of the regular plane hexagon model of the benzene molecule, Phys. Rev. 1934, 45, 706-714. 
Figure S1. Mass-weighted normal mode vectors of 30 vibrational modes of $\mathrm{C}_{6} \mathrm{H}_{5} \mathrm{O}\left(\not{X}^{\circ / \beta} B_{1}\right)$ using Wilson's nomenclature.
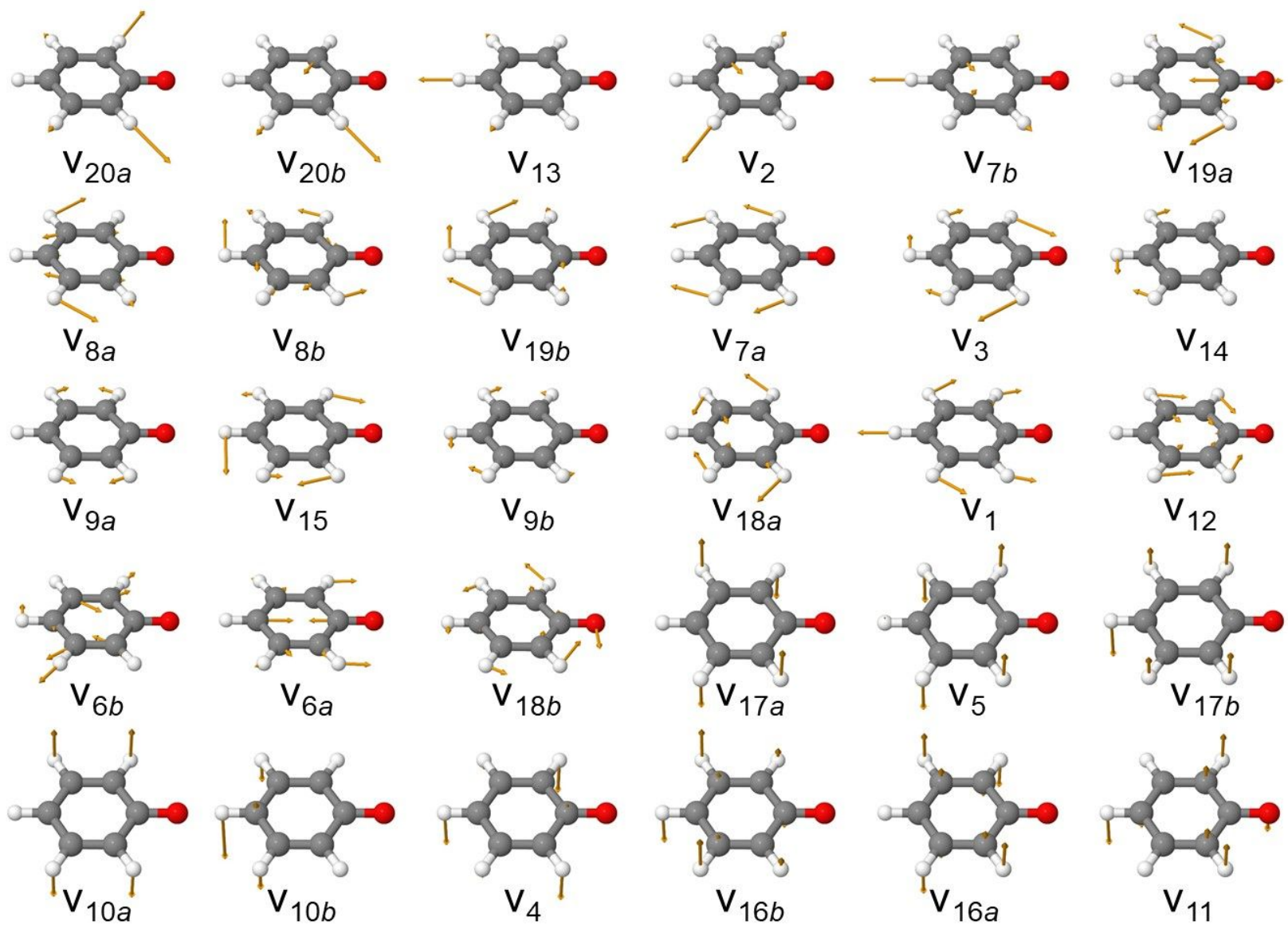